\title{
MONITORING AND REPORTING SYSTEM FOR MUNICIPAL SUSTAINABLE DEVELOPMENT GOVERNANCE IN LATVIA: SUSTAINABILITY OUTLOOK
}

\author{
Jānis Kaulins' ${ }^{1}$, Dr.Geogr., Raimonds Ernsteins ${ }^{2}$, Dr.habil .Paed., \\ Ivars Kudrenickis ${ }^{3}$, Dr.Sc.ing. \\ $1,2,3$ University of Latvia, Environmental Science Dept., Latvia
}

\begin{abstract}
Saulkrasti municipality is the first in Latvia local authority where a sustainable development planning and its governance performance success measurements have been completed, based on sustainability indicators, realised in the frame of research-and-development project. The overall aim was to study municipal sustainable development governance process cycle performance qualities and quantities, including socialecological system studies, planning process, produced documents and their implementation studies as well as studies of construction and testing of necessary IS. The following research methods were complementary used: case study research; approbation research; expert interviews. The data and information basis of measurements were collected using official statistics; information of municipal institutions and enterprises; also private business; inhabitants survey and public monitoring. Monitoring and measurements were based on application of the set of 64 indicators, a comprehensive indicator system (IS), that has been approved and included as an integral part of a mandatory municipal long-term planning document - Sustainable Development Strategy (2013). Weaknesses identified during the first cycle of the full approbation of this existing IS, are revised in the new post-monitoring version of it. Results of the measurements are reflected in the new type of municipal governance document named as municipal Sustainability Outlook - Municipal Sustainable Development Governance Survey. This document is meant to support strategic decision-making and provide municipal collaborative communication with all stakeholders' groups, and, particularly, general society, including also public participation. Sustainability Outlook report is a generalized overview of indicators measurements and their interpretations, which reflects sustainable development governance success by: thematic groups of indicators, sustainability dimensions, mandatory including also governance, in the territory in general. The IS functionally is an essential instrument, being a part of the necessary eventual municipal monitoring program, which are to be developed in the both, general and also in thematic/sectoral development areas (like coastal governance or tourism etc.) of municipality. There would be necessary to comprehend all new and existing IS in planning regions of the country and at the national governance level, in order to form harmonious vertically and horizontally integrated common National indicator system's network, also aiming to involve the public more widely in the local sustainable development aiming process and its governance measurements and evaluation. Importantly, in this way to make the introduction and use of such IS at municipal level in the future simpler and cheaper. Respectively, developed with certain regularity municipal sustainability report, may become an effective municipal governance instrument for the assessment of implementation of different planning documents and general performance of development governance in each local territory, within context of wider public needs and public participation.
\end{abstract}

Keywords: sustainable development, governance, municipal monitoring, indicator system, sustainability reporting.

JEL code: Q56; Q58

\section{Introduction: sustainable development planning practice}

Sustainability concept in its modern understanding got wider resonance through the Agenda 21 document adopted during the world sustainability conference in Rio in 1992 that later has been transposed to the local level (Prescott-Allen, 1995; Brugmann, 1996 etc.) and widely implemented in many countries as Local Agenda 21 documents. It has been followed by refection of sustainable development (SD) principles in policy guidelines and practical recommendations (UNEP, ICLEI, 1996), requesting: monitoring as a mandatory factor of SD; public involvement in all stages of SD and its planning process; and calls for integrative nature of SD. Spatial development planning system in Latvia, to a large extent, is based on Agenda21 and Local Agenda21 guidelines, however often only formally (Kaulins, 2015). Already in the normative level, Law on Development Planning 
System (Saeima, 2008) foresees a requirement for planning documents monitoring. Law on Spatial Development Planning (Saeima, 2011) determines that for medium and short-term documents monitoring must be done using indicators system (IS) that has to be included in the planning documents composition. Besides, parameters listed in environmental report of specific planning document's strategical environmental impact assessment shall be monitored, as well. There are not envisaged other types of monitoring requirements, neither support measures for monitoring in normative acts. This is not in line with emphasized sustainability principle compliance requirement present in mentioned acts of legislation because action monitoring and success evaluation of development strategy as the main sustainable development planning document is not envisaged. Despite that, there is a number of municipalities, which are interested into in-depth assessment of their development strategy, in order to upgrade medium-term planning guidelines and update and make more efficient local action programs. Important here is communication aspect, providing precise and reliable information for decision makers and society.

There was elaborated research-and-development (R\&D) process approach with the overall aim to study municipal sustainable development governance (SDG) process cycle performance qualities and quantities, including research tasks for territorial social-ecological system studies, planning process, produced documents and their implementation studies as well as development tasks for the studies of construction and testing of necessary IS. The following research methods were complementary used: (1) case study research (CSR), realizing document studies and field studies, including interviews with target group representatives (2) approbation research for testing R\&D results; (3) expert interviews beyond the CSR frame. Thus, Saulkrasti Municipal Council in 2012, when starting development of its Sustainable development strategy, has taken decision to include SD and its governance IS in the document as it was methodologically developed by the researchers of the University of Latvia. IS was developed (Kaulins, 2015) and approved in 2013 with the decision of municipal council as the first of a kind monitoring system in Latvia, which rooted directly in the planning process and planning documents guidelines (KBLC 2013). A set of our publications has been dedicated to the system itself and later also to the results of specific indicator measurements in Saulkrasti municipality (for example, Kaulins, 2015). However, the same level of recognition has to be paid to results communication to the public, thus fostering its involvement in use and further development of the system. The approach of SD and its governance assessment in Saulkrasti was based on indicator method (Kaulins, 2015), that allowed to create a system, which, from one side, is based on four basic sustainability dimensions - natural, economic, social and governance environment, highlighting mutual integration of these dimensions, and connecting them with so called priority integrative municipal problem areas, which identification, on its turn, has been carried out based on long term strategic guidelines.

In 2015 and 2016 in the frame of the State Research Program SUSTINNO full system measurements were done. In 2017 a concept of integrative summary report - Sustainable development governance survey (SDGS) - was developed to reflect all results, based on similar elaborations started on Environmental governance Outlook proposals (Ernsteins, 2016). It is innovative for Latvia pre-planning and target groups communication proposal, novel is also a developed SDGS report itself. This Sustainability Outlook, as SDGS is called in short, is a generalized overview of indicators measurements, which reflects sustainable development 
governance success by: thematic groups of indicators, sustainability dimensions, and governance in the territory in general.

Shields (see Fig. 1) has justified generalization principles of information provided by indicators and their system (Shields et al., 2002) at the same time indicating, that all received information must be made public. SDGS consists of separate indicator reports (1st level of pyramid) and it forms 2 nd and 3rd level of pyramid. The final version of the report is the subject of public discussion process, taking into account at least the requirements of formal consultation procedure (Cabinet, 2009).

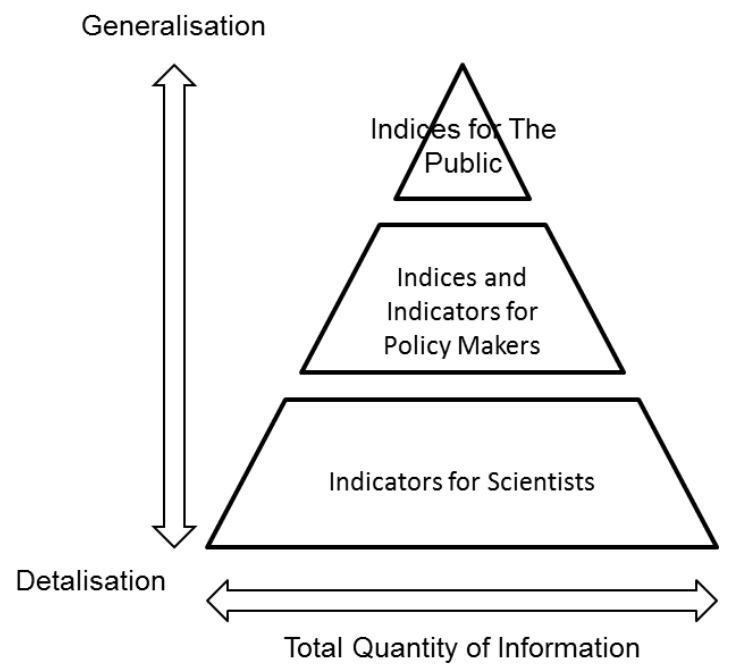

Source: Shields et al., 2002

Fig. 1. Indicator information pyramid according to the target groups

\section{Methodology: indicator's measurements and processing for reporting}

Research-and-development (R\&D) approach was used as methodological framework for indicator system (IS) studies in Saulkrasti as a pilot municipality in Latvia. Necessary sociological studies (interviews, public survey, round-table discussions) were done by university researchers already during initial design period of the municipal IS (2011-2012). Additional methods included stakeholder interviews during implementation of IS in 2014, before the measurements of indicators have started. Measurements were finalized into the format of each individual indicator structured reporting (approximately 3-4 pages for each and about 160 pages in total) to be professionally used by municipal staff, experts. But, in order to prepare summary information for main stakeholders and general public, there have been designed and drafted a new type of public discussion and pre-planning document - Sustainability Outlook, which again is a novel approach in the Latvian municipal practice.

IS as it has been initially designed and officially approved by the municipal council in 2013 included 63 indicators, which were grouped according to traditional municipal planning sectors that, in turn, were grouped into four sustainable development dimensions (natural environment, economic, social environment and, a mandatory also governance dimension), finally a separate integral or strategical indicators group was introduced too. For each indicator a comprehensive, precise measuring methodology was developed; together with general directions for use of the indicator system. These provisions were summarized in a User's guide manual (KBLC, 2013). The data and information basis of measurements now was made up of: official statistics; information provided by municipal institutions and enterprises; information provided by private business; 
inhabitants survey; and public monitoring. Besides, the results of survey conducted in the frame of municipal planning process in 2012 were used, where they were relevant to the measurements done in 2014. In majority of cases data were available as requested by the indicators methodology, although there were some differences. Data were processed in 2015 and in 2016 they were compiled in the indicators initial report (Kaulins, 2016).

Further on the second part of the research-and-development framework are to be elaborated the municipal action policy and planning initiatives and documents - and following methodological principles and approaches developed and applied. The research and assessment results are to be summarized into generalized and integrative survey about measurements of indicators, which in a concentrated way reflects current strategic sustainable development governance success and shortcomings by: sustainability dimensions; regarding long-term strategical elements formulations (main goal, goals, long term action directions); and governance of the territory in general. Such type of reporting, which currently is not a mandatory municipal document, potentially has to be approved and disseminated by the municipal council, besides it is advisable that it is first of all publicly discussed and so contributed for its data and planning adjustment interpretations, before getting its final shape and further municipal planning conclusions.

The content of sustainability report is formed of the following sections: 1) Saulkrasti municipality sustainable development governance indicator system that includes short description of the system and indicators table; 2) the course of indicator measurements in 2012-2014 that includes technical information about measurement performers, data sources etc.; 3) Saulkrasti municipality sustainability general characteristics: natural environment, economic environment, social environment, governance, and integral (strategical) indicators. 4) general characteristic of Saulkrasti municipality's sustainability; 5) resume by sustainability dimensions and assessment of the results from perspective of sustainable planning guidelines. Document ends with public needs orientated summary about sustainability of the Saulkrasti municipality development in 2014.

The most important methodological element in the composition of SDGS is structure of the dimensional description, which is provided in the 3rd section. Dimensional description is started with explanation, what is its content and which structural elements of the municipality are relevant to the specific sustainability dimension. It is followed by sustainability situation description of a specific dimension, illustrated by the most interesting results of indicator measurements providing either very typical or unexpected results. A concluding part of description provides general conclusions and highlights positive and negative (which needs specific attention) factors of a dimension. Description is illustrated by graphical representation of sustainability measurements. Conclusion part provides guidance in which direction decisions must be made, in order to improve the situation in specific sustainability dimension, as well as it provides a concrete list of recommended actions. Some considerations are made on necessary additional information for better planning of further actions. A final part of the section reflects public and experts' opinion where such have been expressed, as well as, considering the long process of information processing, a short report is given about what has happened since 2014, if there were some crucial, visible changes, comparing with the measurements.

After presentation of the material in the municipality and discussion with municipal leadership And specialists, all results and recommendations were forwarded to municiplaity for the further actions to be done, including for communication with society's target groups, as well as for 
discussion on interpretation of survey results and development of proposals for annual update of the municipal development program (medium-term document for 7 years' period).

\section{Municipal policy development: results and discussion 3.1. Dimensional sustainability assessment in Saulkrasti municipality}

Assessments of all sustainability dimensions are formed following the structure described in the previous chapter. For illustration, integrative elements of economic dimension assessment are provided here. In general, economic environment sustainability is assessed as limited. Situation with municipal budget develops positively, however a base for budget (private sector development) is not balanced. In general context, successful are activities of the Skulte harbour. Tourism, which is the second strategical priority of the municipal development, is stagnating. There is not identifiable real movement towards another strategic goal targeted to receiving a resort status. These processes are developing in the circumstances of an ever-increasing labour supply deficit. However, a set of preconditions exists for successful development: good work of tourism information centre, developed transport infrastructure (except pro-environmental bicycle infrastructure), increase of a total number of visitors to the municipality, despite decrease of nonresident flows. Opinion of inhabitants and guests confirm this assumption, because the main asset of the municipality - its coastal area - is mostly positively evaluated both in terms of environmental, and improvement aspects.

Positive. In general budget situation is seen as favourable and developing in desirable direction. Municipality has overcome consequences of the financial crisis of 2008. After 2013 significant growth of external co-financing of infrastructure projects is observed; new business areas have been developed, competitiveness of municipality economy has grown; continuing port development, what has contributed substantial capital investments in the local infrastructure. Progress is seen as regards practically all indicators; successful results are seen in work of tourism information centre; positive evaluation of the coastal environmental situation and infrastructure, however, potential for further significant improvements has been recognized.

Negative, where attention has to be paid. There exists ever-increasing lack of labour supply in the municipality, which will influence human resources-intensive tourism sector development. Return of long term investments into budget is a very slow, similarly, as in the majority of municipalities of Latvia, thus a local budget is not sufficient to ensure dynamic infrastructure development. There is increase in number of jobs only in public sector. Railway is poorly adjusting to the needs of permanent residents of the municipality; practically there does not exist bicycle lanes network; small number of accommodation and catering service providers does not match with planned priorities of the municipality economic development. There is lack of unique offer, including in health tourism. As consequence - non-resident attendance decline. In general, development of tourism sector is weak and unbalanced, some its segments become weaker, while others uncompetitive. There is lack of interest in eco-certification.

Where additional information is needed. There is a need of data on municipality GDP sectoral breakdown for the assessment of the sectoral input in development; actual job situation in small enterprises; actual situation in small tourism enterprises regarding seasonality, workload, and employment. Recommended actions. Strategical goals of municipal development must include measures for: improvement of demographic structure; creating favourable circumstances for young families with children; necessary bicycle infrastructure development action plan. 


\subsection{Integrative overall assessment}

The overall assessment of sustainable development shows relatively good sustainability indications as regards natural environment, on the backdrop of somewhat delayed social and economic development. However, there could be recognized a certain balance in the ratio of the sustainability dimensions, with a slight predominance of the natural environment. This is a positive sign, at the same time it also means that without changing the basic socio-economic conditions, the situation will not change significantly. Here, as a critical factor, is a shortage of development territories and natural resources, together with the poorly developed region's strategic economic sector - hospitality in the tourism sector. The planning of the municipal development policy considers these three issues as highest priority. A significant sustainability reserve lies in better infrastructure of the "Gardeners' communities" and involving inhabitants of these areas in the public and economic processes of the municipality. The "Gardeners' communities" are made up of several hundred tiny land properties with a very small area - typically 600 square meters, which are concentrated in certain areas of the municipality and which mostly belong to the inhabitants of the capital city of Riga, who mostly stay here in the summer. The influence of Riga's proximity is dual. On one hand, it reduces the economic activity in the municipality and does not replenish municipal budget. On other hand, it is a socially stabilizing factor, reducing the dependence of local welfare on its limited capacity and, also reducing effects of external factors on fragile local economy.

Municipality's Sustainable Development Strategy defines three development goals: 1) activities towards obtaining a resort status; 2) effective port activity, and 3) adequate for inhabitant needs educational, cultural and sport infrastructure. Progress towards the first goal is limited, as seems the entrepreneurship sector does not recognize enough potential in this area, but the local administration has not taken sufficient management decisions that could trigger the situation. The self-organization of entrepreneurs has not been active either. With regard to the port activities, management decisions have fostered investment in port development and progress towards the goal is successful Certain sustainable development threat is seen in growing environmental impacts of port operations. There is currently no comparative measure that would allow for the long-term evaluation of the availability and assessment of various social infrastructure components; this will be possible through the second cycle of measurements of indicators. However, it can be argued having compliance with the regional development centre statuss, with the exception of certain formal positions in the field of public administration.

The main conclusions on the sustainability of the municipality are as follows: most indicators indicate a moderately positive trend towards sustainability; none of the calculated indicators indicates a significant mismatch of management with regard to sustainability as the basic setting for governance development. The municipality is recovering from the economic crisis as a factor negatively affecting sustainability. Critical factors of sustainable development of the municipality are: lack of development territories and labour force reserve; poorly developed economic sector - hospitality services. A significant sustainability reserve lies in the improvement of the infrastructure for the areas of "Gardener communities" and the involvement of the inhabitants of these territories in the social and economic life of the municipality. 


\subsection{From indicator system and sustainability report towards municipal monitoring}

The Municipal Monitoring System should reflect implementation of all three planning periods (long-term, medium and short-term) policies and their planning documents. Each specific type of planning document has its own type of parameters (Fig. 2). Implementation of sustainable and integrated management requests equal respect to all stages of the governance cycle. Thus, the research results of the interactions of natural sciences and social sciences must be transformed into the development of a local level science-policy-practice process and content development. The mediator, in the particular case is science sector, needs to be presenting in the form, terminology and procedural context that is perceived by the target group. Unfortunately in general, the results of significant scientific research still in the Latvian situation are used insufficiently in the realization of the municipal governance. Considering the fact that there is a certain similarity between the organizational and informative aspects of indicators and resultative pointers (RP) measurement, but the difference is basically only in the methodological detail, it is purposeful to develop a multi-component, unified monitoring system and mechanism for its implementation and maintenance (Kaulins, Ernsteins, 2018). Indicators operate in the long run and, in general, do not depend on the guidelines contained in the planning documents. A separate group of strategic or integrated indicators characterizes the sustainability of the site and sustainable development in general; some of them may not be directly attributed to the strategic objectives set out in the long-term planning documents but characterize the sustainable development of the territory as a whole.

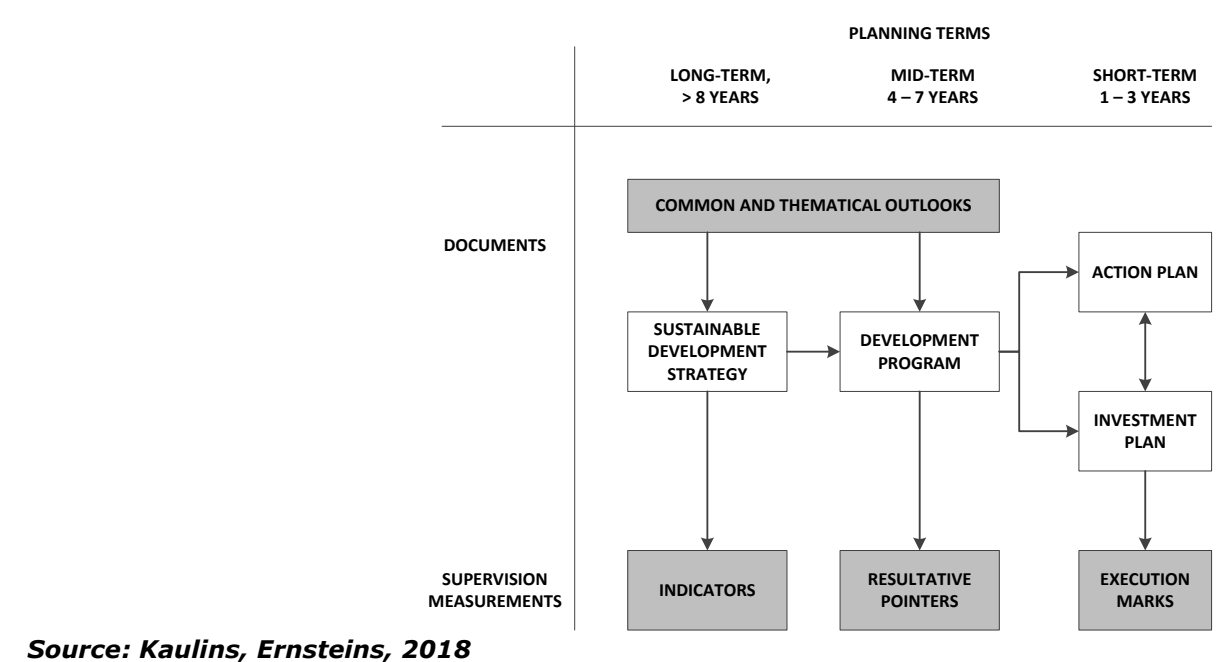

Source: Kaulins, Ernsteins, 2018

\section{Fig. 2. Monitoring system tools for development planning documents}

The essential feature of the IS is the early warning. Another important function is communication with the public, informing, educating and involving in management of the IS. The second set of parameters consists of RP, which essentially illustrate the consequences of the implementation of the planning document. Their task is to observe how progress is being made towards the established medium-term goals and how the directions for action defined within them are implemented. In some respects, RP is also a prognostic tool, but the forecast is limited by the guidelines and deadlines set in the planning document. Practice confirms that a large part of the RP sets basically the characteristics of the indicators, which allows to expand the specific PP functions up to the indicator level. This can be done by including the relevant to RP indicator system and 
developing the appropriate methodological provision. The third set of parameters is an execution pointers (action marks) that illustrates the execution of specific actions within the deadline and its status. Typically, this can be reduced to a non-numeric character of a binary "executed-nonfulfilled" type. Such a parameter can by definition not be an indicator and, in fact, neither RP. However, among the performance indicators, it is possible to select parameters with a numerical nature, such as, for example, the amount of funding received or the amount of activities implemented. In this case, there will be a partial overlap of the set of performance indicators with the PP set.

A significant subset, which can include all three types of previously described parameters and which is characterized by a specific way of obtaining information, are public monitoring parameters. They are characterized by the acquisition of data in a systematic public involvement process - by volunteers performing field observations, surveys, and more activities. It's possible to talk about citizen science, when people without special knowledge, after some guidance/ training, are purposefully involved in solving of scientific problems or, in the case of municipal monitoring, solving economic and management problems with scientific methods. Public monitoring not only provides access to data that are otherwise unavailable, but also plays an important educational role and enhances public confidence in monitoring results in particularly and in local governance in general.

\section{Conclusions}

1) The practice of using the Sustainable Development Governance (SDG) IS in Saulkrasti municipality suggests that it can be the basis for monitoring, evaluation and re-planning of longterm territorial development planning documents, also assessing overall sustainability and preparing municipal governance recommendations in the frame of governance cycle. The IS based Sustainability Outlook provides an adequate understanding of progress towards SD in the context of SDG goals.

2) The experience gained during the first measurement and assessment cycle is helping in developing new IS for the needs of municipalities, making them to be more efficiently applied and better integrated horizontally and vertically with other planning documents of different governance levels.

3) The IS based Sustainability Outlook for SD governance demonstrates options of successful integration of scientific approach into the monitoring system and measurements' performance as well as overall assessment of SD for the preparation of decision-making recommendations. The role of science can be stressed in providing information to various local target groups on essential topics, being usually diffuse or difficult to access or understand.

4) The proposed municipal monitoring system combines assessment of SD and monitoring (supervision) of planning documents. Public monitoring component here ensures the acquisition of important, but otherwise inaccessible information, in combination with benefits of public involvement. A practice of regular publicly discussed reports shall increase public awareness and confidence in local government.

\section{Acknowledgement.}

The publication was prepared in the framework and with financial support of National research program SUSTINNO project "Environmental diversity and sustainable governance". 
Acknowledgement shall be expressed to contributing project partners - Kristine Gaugere and Anita Lontone from the University of Latvia, and Normunds Licis from Saulkrasti municipal council.

\section{References}

1. Brugmann, J. (1996) Sustainable Development Planning: Assessing Progress Towards an Applied Methodology. Environmental Impact Assessment Review. Boston, MA: Massachusetts Institute of Technology (MIT).

2. Cabinet (2009) The Cabinet of Minister's Regulation No.970. at 25.08.2009. Latvia Republic. The Arrangements for Public Participation in the Development Planning Process".

3. Ernsteins R., Kaulins J., Lontone-Ievina A., Zvirbule L., Zilniece I. (2016). Environmental Integration Approach Complementary to Environmental Governance Outlook Development as Disciplinary Approach (in Latvian). Proceedings, $18^{\text {th }}$ International science conference, Liepaja University, Liepaja, Latvija, May 2015, pp. 325-337.

4. Kaulins J., Vesperis V., Dombrovskis V. (2013) Latvia's Sustainable Development Strategy: The Supervision report. Cross-sectoral coordination center at Cabinet of Ministers. Latvia Republic. Riga, 127 p. (in Latvian)

5. Kaulins J. (2015). Indicators for Sustainable Development Governance (in Latvian). Doctoral thesis. University of Latvija, Faculty of Geography and Earth Sciences, Riga, 160 p.

6. Kaulins J. (2016) The Saulkrasti Municipality Sustainable Development Governance Indicators: Reports on Measurement of 2014. Project SUSTINNO, National research program, 160 p. (in Latvian)

7. Kaulinš J., Ernšteins R. (2018) Municipal Sustainability Monitoring: Necessity and Preconditions for National Sustainable Development Planning Supervision System (in Latvian). In monography (edit. Ernsteins R.) "Sustainable Development Governance and Environment" (in print), University of Latvia, Riga, Latvia.

8. KBLC (2013) Strategy for the Sustainable Development of the Saulkrasti Municipality. Development and Sustainability Indicators for Monitoring the System: User Guide. KBLC LTD., 2013., 140 p. (in Latvian)

9. Prescott-Allen, R. (1995) The Barometer of Sustainability. Victoria, BC, Canada: Project on Monitoring and Assessing Progress Toward Sustainability, 1995

10. Saeima (2008). Development Planning System Law. Accepted at 08.05.2008.

11. Saeima (2011). Territorial Development Planning Law. Accepted at 13.10.2011.

12. Shields, D.J., Solar, S.V., Martin, W.E. (2002) The Role of Values and Objectives in Communicating Indicators of Sustainability. Ecological Indicators 2 (2002), 149-160.

13. UNEP, ICLEI (1996). The Local Agenda 21 Guide. An Introduction to Sustainabie Dvelopment Planning. $218 \mathrm{p}$. 